\title{
Combining water supply and flood mitigation requirements in multi-purpose reservoir optimization
}

\author{
S. Frongia ${ }^{\text {a }}$, S. Liberatore ${ }^{\text {a }}$, G.M. Sechi ${ }^{\text {a }}$, A. Sulis ${ }^{\text {a }}$ and R. Zucca ${ }^{\text {a }}$ \\ ${ }^{a}$ DICAAR Dept. of Civil and Environmental Engineering and Architecture - University of Cagliari - Italy
}

Email:sechi@unica.it

\begin{abstract}
Optimising the planning and management of reservoir systems by integrating multi-purpose objectives has been the subject of extensive research work since the 1990s, especially when the multiple benefits of reservoir system operation (e.g., supplying demand systems) and the reduction of natural risks (e.g., flood mitigation) are to be combined.

The issue is frequently simplified by considering the second requirement (flood mitigation) as a pre-defined constraint working on system operation optimisation and, therefore, modelling for the first requirement (design and management of multi-purpose reservoirs for water supply). The European Flood Directive 2007/60/CE requires that flood-risk evaluation should be in agreement with a cost-benefit analysis and a rational decision-making tool must be used for optimising the flood mitigation system. The study background underlines the importance of the water depth-damage functions as one of the elements of a decision-making tool designed to evaluate the economic damage expected in flood-prone areas.

The assessment and evaluation of potential flood damages in quantitative terms need to reconsider existing flood risk management plans to endorse their approach to reducing potentially damaged areas. This requirement has to be considered in areas affected by heavy flood events, such as Mediterranean areas. In the proposed combined approach WARGI decision support system (DSS) simulates the management of multireservoirs and multi-user systems, considering the resource priorities and users' preferences in the light of hydrological deficiencies and, consequently, water scarcity conditions. A link between the WARGI simulation and hydrologic and hydraulic models defining the vulnerability of flood-prone areas has been constructed in order to verify flood damage reductions and their economic evaluation. The link is used to quantify cost-benefit relations to obtain a rational decision-making optimisation tool.
\end{abstract}

A significant test case has been developed by applying the proposed methodology on the island of Sardinia (Italy). In this region several reservoirs have been built mainly for water supply and hydropower generation. The Regional Flood Mitigation Plan requires the assessment of the impacts of possible changes in reservoir management and the construction of new infrastructures for flood damage reduction. The River Coghinas has been investigated with regard to the interactions of flood mitigation requirements and upstream reservoir management. The river is the pilot basin for the Sardinian Regional Administration's development of the flood risk management plans required by EU and national legislation. In this pilot basin regulation reservoirs are located in the upstream river, and in the downstream floodplain area residential, touristic, commercial, industrial and agricultural areas and different types of roads and infrastructures are located.

Keywords: Decision support system, flood mitigation, reservoir management optimisation 


\section{INTRODUCTION}

The river flooding disasters which have occurred in many countries led the European Commission to develop a harmonised approach towards damage mitigation measures (European Commission, 2007). In the Mediterranean regions flash flooding is the most common type of inundation as the majority of flood events have been induced by intense rainfall occurring in short periods of time and reaching impressive flow rates very quickly (Pistrika, 2014). In addition to climatic and hydrological peculiarities, the shift of population from rural areas to cities increases urbanisation and consequently an emergency or disaster management plan is necessary in terms of preparation, support and reconstruction when natural or man-made disasters occur (Vojinovic, 2008). The European Commission Flood Directive requires a focus on the assessment and management of flood risks: article 7 of chapter IV highlights that the 'Flood Risk Management Plans shall take into account relevant aspects such as costs and benefits', while in chapter III the Directive requires the preparation of the flood hazards maps and the flood risk maps. The flood maps raise awareness of the potential floodplain areas and the resulting water depth maps are the launch pads for economic damage assessment. The potential flood damages estimation should be defined quantitatively to create a rational decision-making tool for flood mitigation policy. Various combinations of structural and non-structural options for flood risk reduction are available to communities. Moreover, water system management can be uploaded in order to face flood events, modifying upstream reservoir-operating rules.

The river Coghinas has been investigated with regard to the interactions of flood mitigation requirements and upstream reservoir management. The river is the pilot basin for the Sardinian Regional Administration's development of the flood risk management plans required by EU and national legislation. As shown in Figure 1 , in this basin regulation reservoirs are located in the upstream river, while in the downstream floodplain area residential, touristic, commercial, industrial and agricultural users and different types of roads and infrastructures are located.

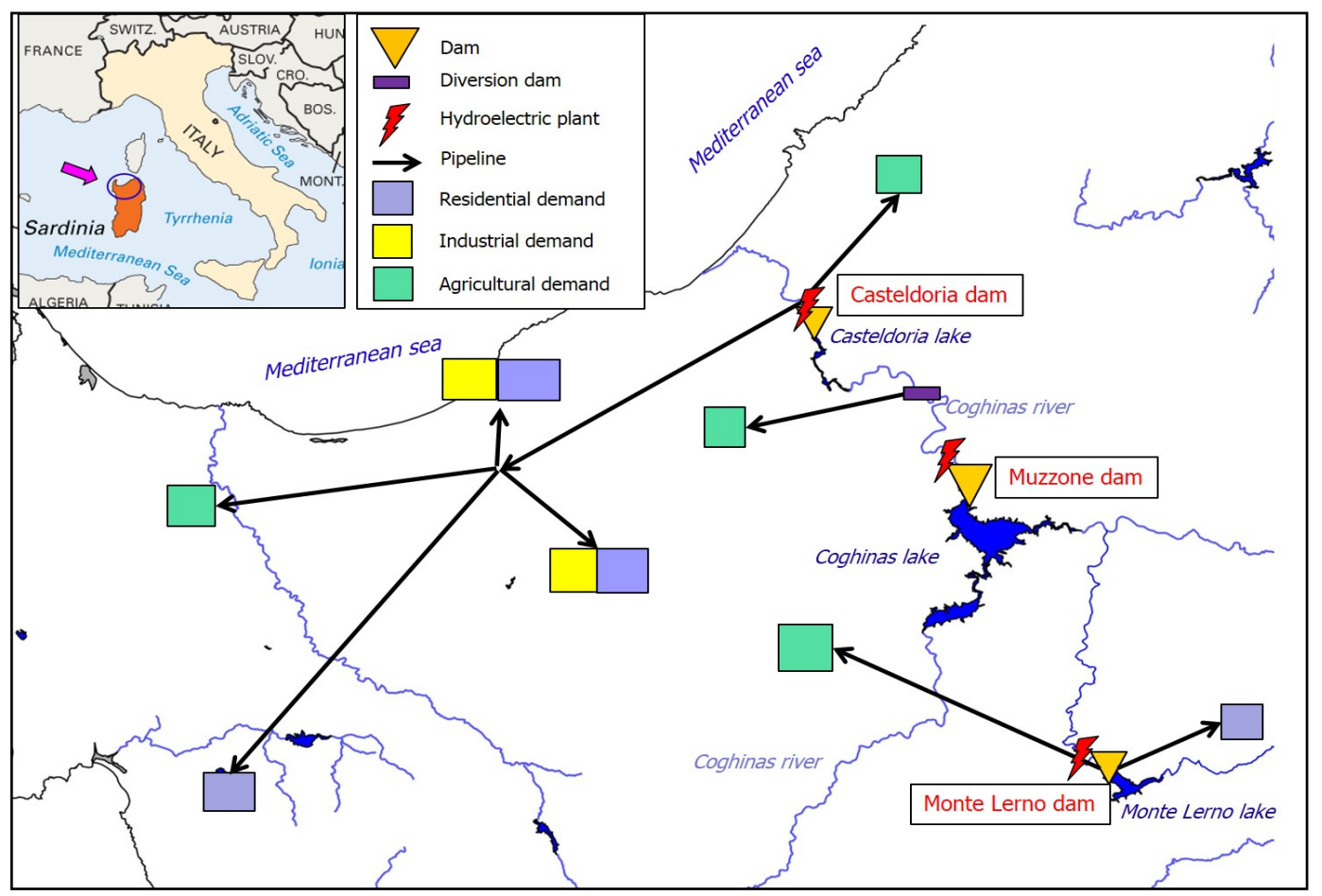

Figure 1. Draft of the North-West Sardinia water supply system

\section{FLOOD DAMAGE ASSESSMENT METHODOLOGY}

Researchers have analysed hydrological data collected during on-site inspections immediately after flood events but synthetic data from 'what if' simulation analysis of potential floods are still used (Jongman, 2012). The present work mainly applies the JRC model (Huizinga, 2007) for flood damage assessment. The JRC model looks at historic events in the whole European area. In the JRC model flood damage assessment considers both types of data: empirical and synthetic. The damage calculation depends mainly on the depthdamage function (absolute or relative damage values are considered) and on types of land use. 
The relative depth-damage function given in Figure 2 represents the percentage of the losses respecting a predefined maximum damage value defined by JRC as country-dependent. The JRC model subdivides the territory into five macro-categories of land use: 1) residential buildings; 2) commerce; 3) industry; 4) roads and infrastructure; 5) agriculture.

In this work some improvements took place relating to land use attribution and the depth-damage curve definition in the JRC model. The land uses were evaluated in relation to CORINE maps (CORINE European

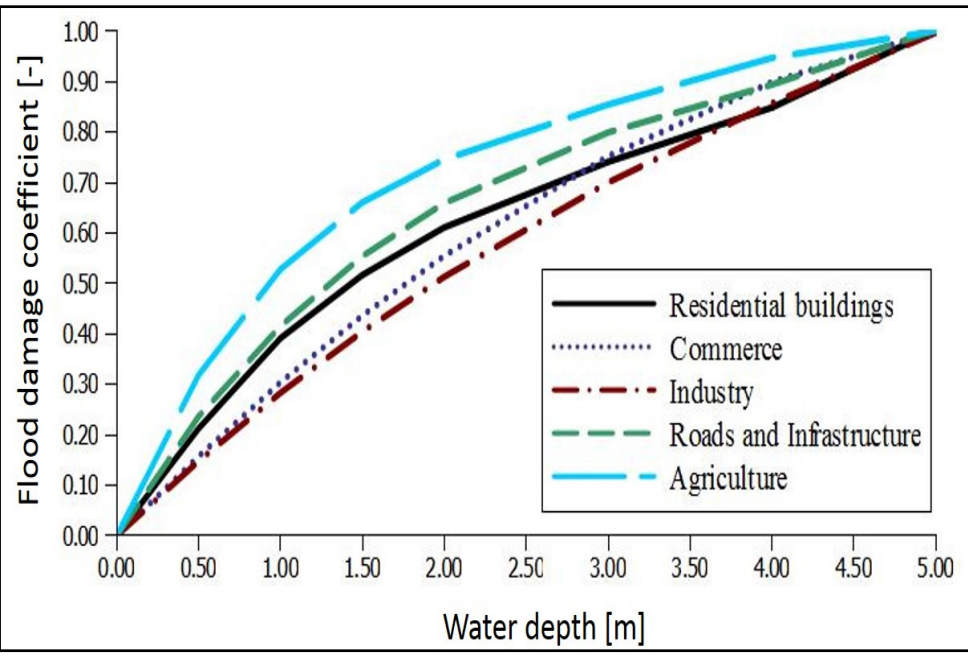

Figure 2. JRC Water depth - Damage values for land use categories.
Project, 2007) and updated to take into account the particular characteristics of Sardinia's territory. The changes are based on details observed through digital ortho-photos and maps of land use. Land use attribution updated the original five JRC model categories, increasing them to 12. In Table 1 land use categories are listed and the respective maximum damage values for units of area are given for Sardinia region (Italy) following the JRC estimation procedure. Land uses from 9 to 12 are considered to be associated only with direct intangible damages.

Table 1. Land use categories and associated maximum damage values.

\begin{tabular}{llcc}
\hline Land use category & Label & $\begin{array}{c}\text { Maximum Damage Value } \\
\left(\boldsymbol{€} / \mathbf{m}^{\mathbf{2}}\right)\end{array}$ \\
\hline 1. & Residential Buildings & $\mathrm{R}$ & 618 \\
\hline 2. & Commercial & $\mathrm{C}$ & 511 \\
\hline 3. & Industry & $\mathrm{I}$ & 440 \\
\hline 4. & Agriculture & $\mathrm{A}$ & 0.63 \\
\hline 5. & Council Roads & $\mathrm{N}$ & 10 \\
\hline 6. & Provincial Roads & $\mathrm{P}$ & 20 \\
\hline 7. & Other Roads & $\mathrm{S}$ & 40 \\
\hline 8. & Infrastructural (Areas with water supply & $\mathrm{T}$ & 40 \\
\hline & network, electricity grid and similar systems) & $\mathrm{H}$ & - \\
\hline 9. & Dams, rivers and similar areas & $\mathrm{H}$ & - \\
\hline 10. & Environmental heritage areas & $\mathrm{K}$ & - \\
\hline 11. & Historical and archaeological heritage areas & $\mathrm{X}$ & - \\
\hline 12. & Area subjected of other intangible damages & & \\
\hline
\end{tabular}

Nevertheless, JRC flood damage assessment methodology requires a validation phase with collected data from historical flood events to confirm outcomes for specific regions in Europe. Here, validation data are related to a flood event which occurred in October 2008 in the south of Sardinia. This area was damaged by a massive rainfall that reached $350 \mathrm{~mm}$ in under three hours and by the flooding of small rivers in the coastal area. Frongia et al (2015) provided a residential building damage curve (Figure 3) considering for each water depth the mean values of recorded damages and adding to them an optimised percentage of standard deviation in order to estimate non-reported data. A reduced range of three metres in water depth is also considered, as observed damage values are included in this value.

Figure 3 highlights that residential damages obtained by the JRC model still remain close to observed mean and maximum values. Nevertheless, Frongia et al (2015) obtained a higher gradient in damage values at lower depth values and at higher values, meanwhile the central part the curve gives almost constant damage values. 


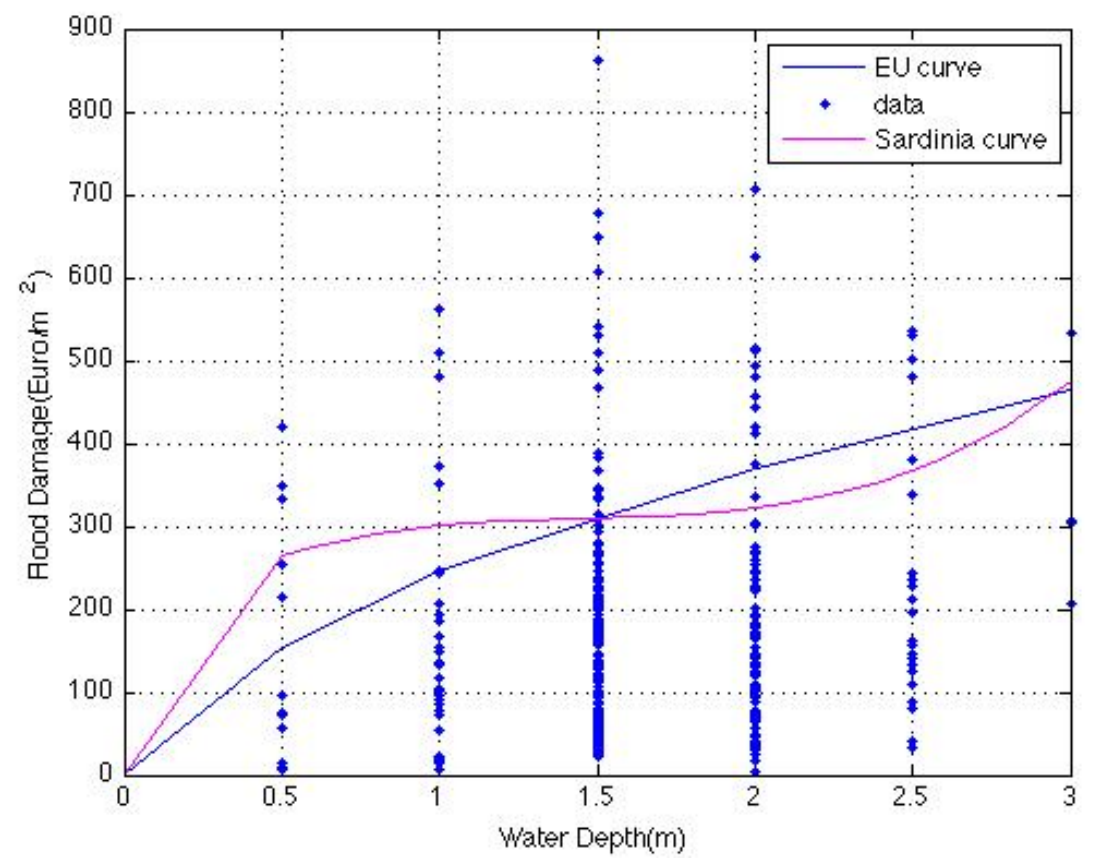

Figure 3. Comparison of JRC and observed (Sardinia-2008) flood depth-damages curves.

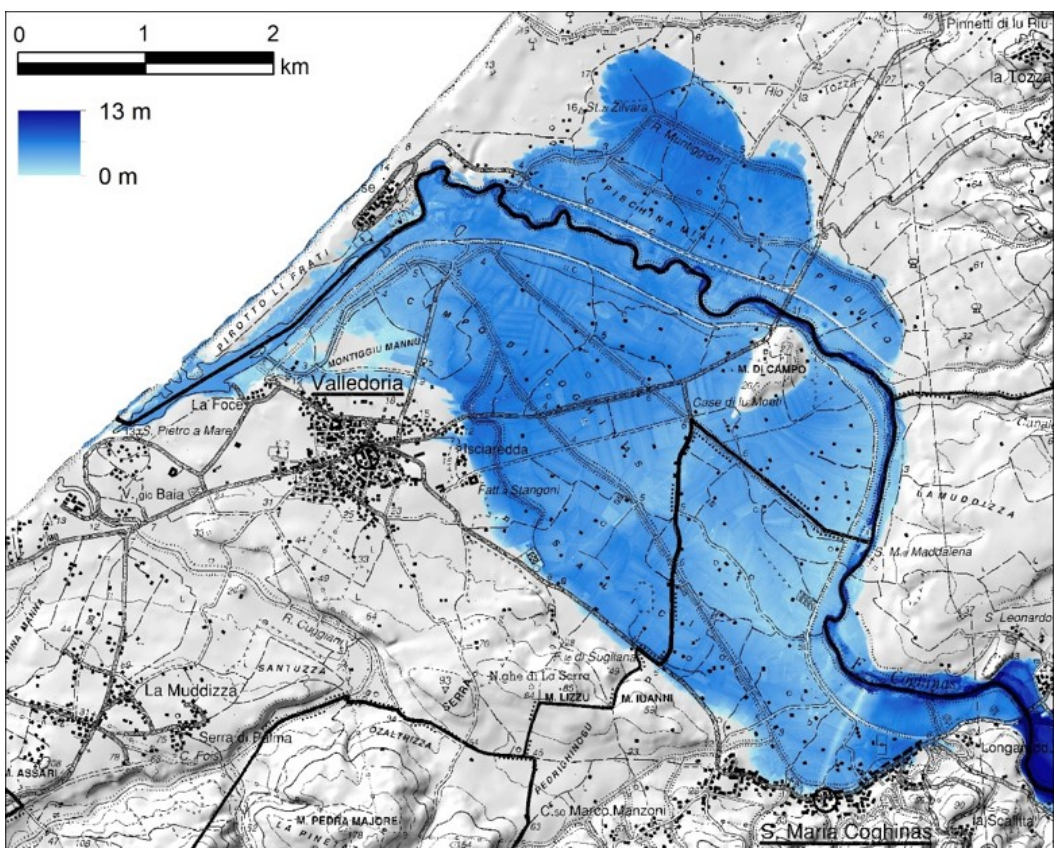

Figure 4. Expected flood-area and water depth in the Coghinas river lowland valley $(\mathrm{Tr}=200)$ - Present situation.
In a following application phase we considered the Coghinas river lowland valley in our attempt to optimise flood-damage mitigation. The potential flood-prone areas were evaluated by synthetically generated floods with an expected return period $(T r)$ equal to 50, 100 and 200 years. Using a GIS-based process we converted the flood-prone areas into a shape file with a cellular grid measuring $3 \times 3 \mathrm{~m}$, allocating a land use category to each cell and the expected water depth for each expected $T r$. Figure 4 gives the expected flood area for $T r=200$ years. Using the revised depthdamage curves for Sardinia, we then calculated flood we then calculated flood
sum of all single-cell damage values. A summary of total expected damages in the present scenario is given in Table 2.

\section{FLOOD REDUCTION BY MODIFYING RESERVOIR-OPERATING RULES}

Flood discharges and associated damages in Coghinas river lowland valley were examined in a further analysis considering the effect of changing the operating rules of Coghinas reservoir to the downstream discharged flood rate. The artificial lake created by the Muzzone dam has a capacity of 240 million cubic metres. The dam was built in 1926 and operates mainly for hydroelectric power production. Moreover, this 
reservoir is the main source for an extended water supply system in North-West of Sardinia, as drafted in Figure 1.

Table 2. Evaluated potential area and damages in Coghinas river lowland valley - Present situation.

\begin{tabular}{|c|c|c|c|c|c|c|}
\hline \multirow{2}{*}{$\begin{array}{l}\text { Label Land- } \\
\text { Use Category }\end{array}$} & \multicolumn{2}{|c|}{$\operatorname{Tr} 50$} & \multicolumn{2}{|c|}{$\operatorname{Tr} 100$} & \multicolumn{2}{|c|}{$\operatorname{Tr} 200$} \\
\hline & Area $\left(m^{2}\right)$ & Damage (€) & Area $\left(m^{2}\right)$ & Damage ( $€$ ) & $\operatorname{Area}\left(m^{2}\right)$ & Damage (€) \\
\hline A & $13^{\prime} 055^{\prime} 381$ & $5^{\prime} 221^{\prime} 925$ & $13^{\prime} 219^{\prime} 059$ & $5^{\prime} 688^{\prime} 986$ & $13^{\prime} 319^{\prime} 222$ & $6^{\prime} 019^{\prime} 251$ \\
\hline $\mathrm{C}$ & 41'021 & 7'581'223 & 41'969 & 9'107'924 & 42'396 & $10^{\prime} 304^{\prime} 961$ \\
\hline I & $53 ' 292$ & $7^{\prime} 193^{\prime} 880$ & $70 ' 330$ & $9^{\prime} 150^{\prime} 344$ & 73'184 & $10^{\prime} 950^{\prime} 897$ \\
\hline $\mathrm{J}$ & $2^{\prime} 075^{\prime} 232$ & - & $2^{\prime} 099^{\prime} 058$ & - & 2'119'113 & - \\
\hline K & $22 ' 310$ & - & $26^{\prime} 687$ & - & $40^{\prime} 014$ & - \\
\hline $\mathrm{N}$ & $42^{\prime} 576$ & $168^{\prime} 716$ & $45^{\prime} 321$ & $204^{\prime} 835$ & $45^{\prime} 786$ & $232 ' 406$ \\
\hline $\mathrm{P}$ & 99'089 & $802 ' 391$ & $104^{\prime} 138$ & 979'904 & $111^{\prime} 261$ & 1'137'800 \\
\hline $\mathrm{R}$ & $114^{\prime} 945$ & $23^{\prime} 916^{\prime} 273$ & $135^{\prime} 434$ & $31 ' 182 ' 354$ & $148^{\prime} 135$ & $37 ' 856 ' 384$ \\
\hline $\mathrm{T}$ & $213^{\prime} 333$ & $3^{\prime} 497^{\prime} 885$ & $217^{\prime} 036$ & $4^{\prime} 054^{\prime} 690$ & $220^{\prime} 499$ & 4'504'593 \\
\hline $\mathrm{X}$ & $634^{\prime} 887$ & - & $656 ' 570$ & - & $673^{\prime} 836$ & - \\
\hline Total & $16^{\prime} 352^{\prime} 066$ & $48^{\prime} 382^{\prime 2} 292$ & $16^{\prime} 615^{\prime} 603$ & 60'369'036 & $16^{\prime} 793^{\prime} 446$ & 71'006'292 \\
\hline
\end{tabular}

In this process of redefinition of management rules for flood lamination, we also had to consider a verification procedure whereby the reservoir could maintain adequate regulation capacity to fulfil all water demands. This aspect is obviously essential for water authorities. The verification process was carried out through a simulation phase using WARGI DSS (Sulis \& Sechi, 2013). Simulation results showed that an organised decrease in the regulation capacity would be the result of keeping open the gates of interception of discharge to downstream of the Muzzone dam in late autumn and at the beginning of winter. These are seasons of main flood events in Sardinia. The adopted regulation rules do not cause significant problems in water supply, ultimately ensuring the absence of deficit for water users.

When defining economic efficiency in terms of reservoir management we also need to consider reservoir use for hydroelectric production and its economic value. By simulation it was also shown that, even if the swirled volume for hydropower production is not affected significantly by restrictions imposed on the stored volume, there are some important issues related to the effect of new regulation hypotheses on hydroelectric production (e.g., variations in the available hydraulic head) and, especially, to the reduced flexibility in the production schedule that might result from the management assumptions here considered.

Table 3. Maximum downstream discharged flood in different scenario.

\begin{tabular}{ccccc}
\hline & Scenario & $\mathbf{T}_{\mathbf{R}} \mathbf{5 0}$ & $\mathbf{T}_{\mathbf{R}} \mathbf{1 0 0}$ & $\mathbf{T}_{\mathbf{R}} \mathbf{2 0 0}$ \\
\hline \multirow{2}{*}{$\begin{array}{c}\text { Max } \\
\text { downstream } \\
\text { discharged } \\
\text { flood }\left[\mathbf{m}^{\mathbf{3}} / \mathbf{s}\right]\end{array}$} & $\mathbf{A E F V}$ & $2^{\prime} 952$ & $3^{\prime} 745$ & $4^{\prime} 460$ \\
\cline { 2 - 5 } & $\mathbf{A 1}$ & $2^{\prime} 119$ & $2^{\prime} 636$ & $3^{\prime} 154$ \\
\cline { 2 - 5 } & $\mathbf{A 2}$ & $2^{\prime} 478$ & $3^{\prime} 033$ & $3^{\prime} 589$ \\
\cline { 2 - 5 } & $\mathbf{B} 1$ & $2^{\prime} 039$ & $2^{\prime} 581$ & $3^{\prime} 097$ \\
\hline
\end{tabular}

Table 3 shows the main results obtained by simulating different reservoir management rules and determining consequent maximum downstream discharged flood values. The Actually Expected Flood Values (AEFV) are given in the first row of Table 3. They are the expected downstream flow rates in the current reservoir management plan. The following rows in Table 3 are related to different management scenarios: Scenario A is related to reservoir management always opening the spillway gates of the dam; Scenario B considers the optimisation in terms of operating the spillway gates. Both scenarios are split into two sub-scenarios related to the maximum storage level that must not be exceeded at the beginning of the flood season: $155.6 \mathrm{~m}$ above sea level in the first case (A1 and B1) and $159.7 \mathrm{~m}$ in the second (A2 and B2). Compared with AEFV, the results in scenario B1 show substantial reductions in downstream flood discharge. This B1 scenario allows the increase of lamination by the reservoir and ensures the safe flow of flood events in the lowland valley up to 50 years' return time. In the following Section 4, Scenario B1 will be considered in the combination of structural and reservoir management mitigation actions.

\section{COMBINING STRUCTURAL AND MANAGEMENT ACTIONS FOR FLOOD RISK MITIGATION}

As previously asserted, we need a rational decision-making tool combining flood mitigation systems in terms of new works and reservoir management rules. A costs-benefits analysis allows definition of the economic efficiency of the considered structural and non-structural flood risk reduction options. 
Here we report main results of an extended analysis, which is available from ARDIS (2015). Structural works for flood mitigation have been previously designed considering AEFV. They are based on four main interventions: 1) a new levee (2,029 m extended) on the right river bank to protect urbanised areas; 2) demolition of the two old bridges inadequate for flood flow; 3) improvements of existing levees on the left river bank (total length equals 8,495 m); 4) improvements in drainage works of lower level areas. The realisation of this pure structural mitigation scenario in actual management conditions requires a total economic investment of about 21.7 million Euros. The annual maintenance costs also account for 274,000 Euros per year. A new economic evaluation is therefore necessary to recalculate the potential flood damage reduction following this structural intervention scenario. Results are given in Table 4.

Table 4. Evaluated potential area and damages in Coghinas river lowland valley - After mitigation.

\begin{tabular}{|c|c|c|c|c|c|c|}
\hline \multirow{2}{*}{$\begin{array}{l}\text { Label Land- } \\
\text { Use Category }\end{array}$} & \multicolumn{2}{|c|}{$\operatorname{Tr} 50$} & \multicolumn{2}{|c|}{$\operatorname{Tr} 100$} & \multicolumn{2}{|c|}{$\operatorname{Tr} 200$} \\
\hline & $\operatorname{Area}\left(m^{2}\right)$ & Damage (€) & $\operatorname{Area}\left(m^{2}\right)$ & Damage (€) & $\operatorname{Area}\left(m^{2}\right)$ & Damage (€) \\
\hline A & 4'319'298 & $2^{\prime} 427^{\prime} 457$ & $4^{\prime} 357^{\prime} 614$ & 2'542'281 & 4'396'981 & $2^{\prime} 634^{\prime} 604$ \\
\hline $\mathrm{C}$ & $18^{\prime} 890$ & $6^{\prime} 669^{\prime} 257$ & $19^{\prime} 136$ & 7'430'968 & 19'359 & 7'956'705 \\
\hline I & $11^{\prime} 947$ & $3^{\prime} 333^{\prime} 775$ & $11^{\prime} 974$ & $3^{\prime} 402^{\prime} 500$ & 11'983 & 3'843'127 \\
\hline $\mathrm{J}$ & $2^{\prime} 437^{\prime} 801$ & - & $2^{\prime} 542^{\prime} 692$ & - & $2^{\prime} 616^{\prime} 783$ & - \\
\hline K & $32^{\prime} 083$ & - & $33^{\prime} 679$ & - & $34 ' 736$ & - \\
\hline $\mathrm{N}$ & $27 ' 529$ & $218^{\prime} 202$ & $27^{\prime} 667$ & $235^{\prime} 546$ & $28^{\prime} 629$ & $252^{\prime} 514$ \\
\hline $\mathrm{P}$ & $14^{\prime} 940$ & $158^{\prime} 655$ & $21 ' 288$ & $225^{\prime} 245$ & $23^{\prime} 967$ & $291 ' 544$ \\
\hline $\mathrm{R}$ & $47^{\prime} 618$ & $23^{\prime} 306^{\prime} 680$ & $53^{\prime} 437$ & $16^{\prime} 892^{\prime} 655$ & $58^{\prime} 371$ & $19^{\prime} 842^{\prime} 025$ \\
\hline $\mathrm{T}$ & $75^{\prime} 514$ & $2^{\prime} 312^{\prime} 239$ & $78 ' 287$ & $2^{\prime} 528^{\prime} 998$ & $80 ' 929$ & $2^{\prime} 742^{\prime} 693$ \\
\hline $\mathrm{X}$ & $618^{\prime} 436$ & - & $635 ' 210$ & - & $648^{\prime} 948$ & - \\
\hline Total & $7^{\prime} 604^{\prime} 057$ & $28^{\prime} 426 ' 264$ & 7'780'984 & $33^{\prime} 258^{\prime} 193$ & 7'920'688 & $37^{\prime} 563 ' 213$ \\
\hline
\end{tabular}

Moreover, the comparison between the present scenario and the structural mitigation needs a costs-benefits analysis as a decision-making tool. Obviously, the realisation of the mitigation measures should give back an amount adequate to justify their cost. Economic analysis shows that achievement of a balance between benefits and costs needs about 40 years after implementation of the intervention, as highlighted on the left side of Figure 5. Results in terms of flooded land reduction are given in Figure 6.
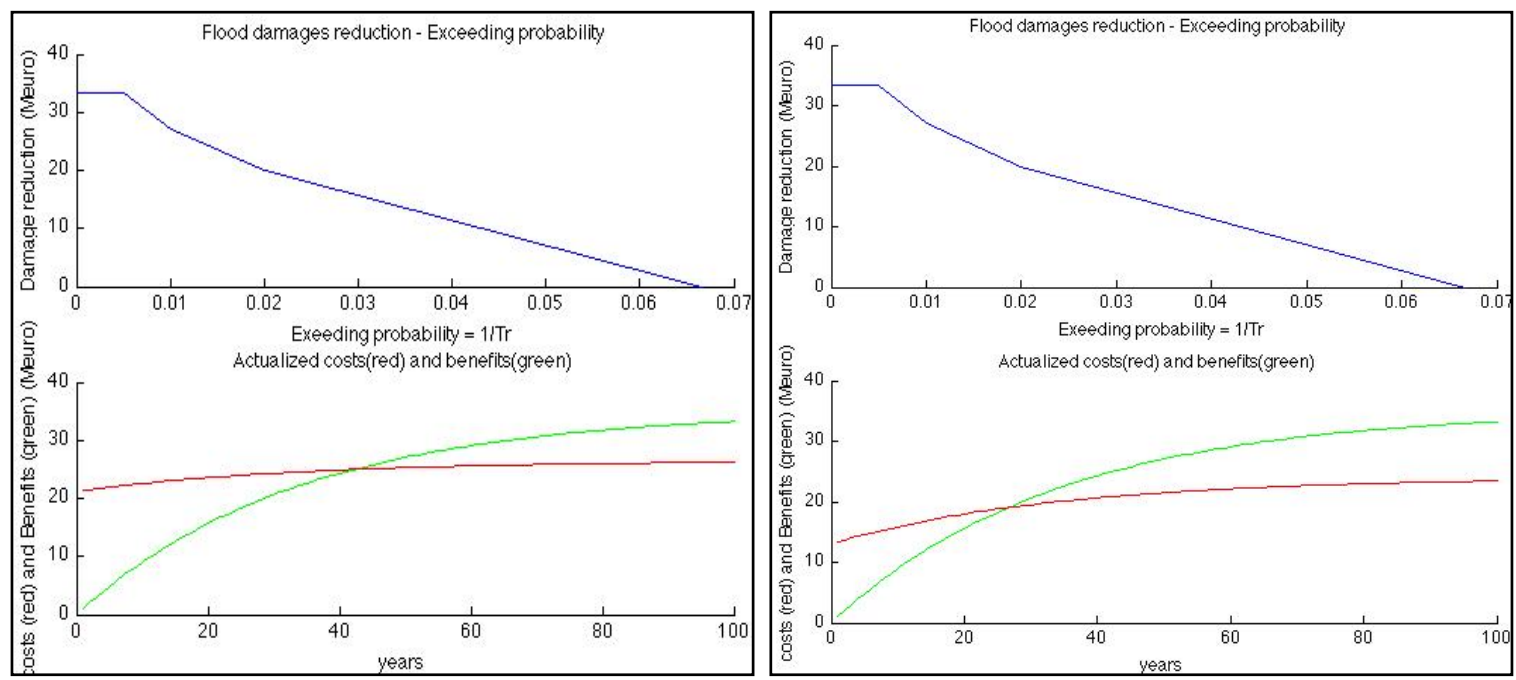

Figure 5. Flood damages reduction curves and cumulative present value of costs and benefits of structural intervention (left) and combined reservoir management and structural intervention (right).

In a second design phase, the combination of modified reservoir management to reducing floods and limited structural intervention was then considered. The new embankment works were consequently reduced and structural interventions were estimated to cost 13.6 million Euros. Annual maintenance costs were equally reduced to about 137,000 Euros. The reduction in energy production by the hydroelectric plant in the reservoir was quantified as about 300,000 Euros per year. The achievement of a balance between benefits and costs is reduced to about 25 years after implementation of the intervention, as highlighted on the right side of Figure 5. The combination of modified reservoir management rules and reduced structural intervention is then highlighted as the optimal combination for flood mitigation in the Coghinas lowland valley. 


\section{CONCLUSIONS}

The potential flood damage estimation requires evaluations in quantitative terms and a rational decisionmaking tool for defining the mitigation systems in terms of new works and rules to recommend to water

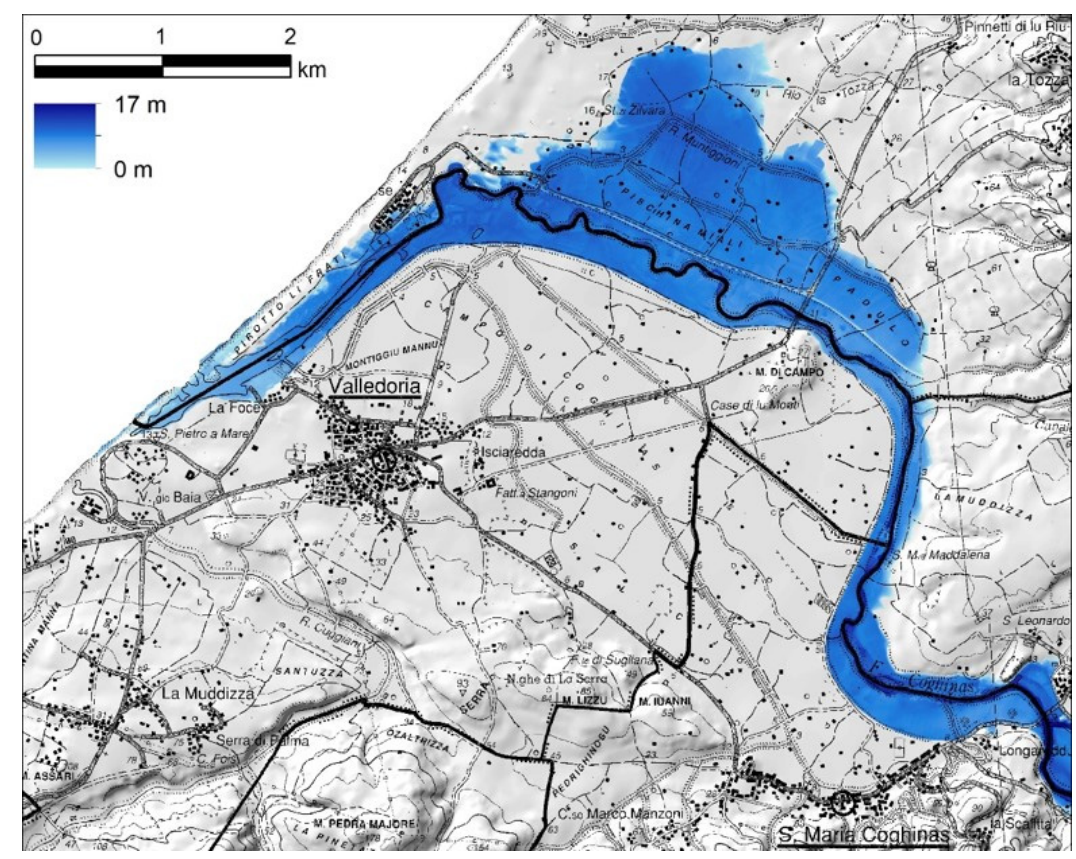

Figure 6. Expected flood-area and water depth in the Coghinas river

\section{lowland valley $(\mathrm{Tr}=200)$ - After mitigation.} system authorities. Various combinations of structural and non-structural flood risk reduction options are frequently available to communities. Assessment and evaluation of the potential flood mitigation options need to reconsider existing flood risk management plans by verifying reservoir management to reduce risk in potential flood areas. In the proposed real-case analysis the combination of reservoir management rules and structural intervention is highlighted as the optimal combination for flood mitigation in the river lowland valley.

\section{ACKNOWLEDGEMENTS}

This research was developed with the financial support of the Agenzia di Distretto Idrografico of the Regional Board of Sardinia (Italy).

\section{REFERENCES}

ARDIS (2014). Progetto di Piano di Gestione del rischio alluvioni, Hydrographic District - Regional Board of Sardinia, Cagliari, http://www.regione.sardegna.it/autoritadibacino/pianificazione/

CORINE European Project (Coordination of information on the environment) - EEA Technical report. European Environment Agency. Copenhagen (2007). ISSN 1725-2237, http://www.eea.europa.eu/publications/technical_report_2007_17

EuropeanCommission. (2007, 23 October). EU Directive 2007/60 on the Assessment and management of flood risks. Official Journal of the European Union.

Frongia S., Liberatore S., Sechi G.M. (2015). Flood Damage Risk Assessment Optimizing a Flood Mitigation System, Proceedings of $9^{\text {th }}$ EWRA Conference, Istanbul.

Huizinga, H. C. (2007). Flood damage functions for EU member states - JRC-Institute for Environment and Sustainability - HKV Consultans Report

Jongman B. H. H. (2012). Comparative flood damage model assessment: towards a European approach. Natural Hazards and Earth System Sciences , 3733-3752

Pistrika A. (2014). Flood Depth-Damage Functions for Built Environment. Pistrika, A., 2010. Flood Damage Estimation based on Flood Simulation Scenarios and a GIS Platform. European Water; 30: 3-11

Sulis A. \& Sechi G. M. (2013). Comparison of generic simulation models for water resource systems, Environmental Modelling \& Software 40, 214-225.

Vojinovic, R. K. Price and Z. (2008). Urban flood disaster management. UNESCO-IHE, Delft, The Netherlands. 